\title{
Role of Damage-Associated Molecular Patterns in Septic Acute Kidney Injury, From Injury to Recovery
}

\author{
Pierre-Olivier Ludes ${ }^{1,2 *}$, Charles de Roquetaillade ${ }^{3,4}$, Benjamin Glenn Chousterman ${ }^{3,4}$, \\ Julien Pottecher ${ }^{1,2}$ and Alexandre Mebazaa ${ }^{3,4}$ \\ ${ }^{1}$ Department of Anesthesiology and Intensive Care, Hautepierre Hospital, Strasbourg University Hospital, Strasbourg, \\ France, ${ }^{2}$ EA 3072, Mitochondrie Stress Oxydant et Protection Musculaire, Faculté de Médecine, FRU 6702, Fédération de \\ Médecine Translationnelle de Strasbourg (FMTS), Strasbourg, France, ${ }^{3}$ Department of Anesthesiology and Critical Care, \\ Hôpital Lariboisière, DMU Parabol, APHP.Nord, Paris, France, ${ }^{4}$ Inserm U942 MASCOT, Université de Paris, Paris, France
}

OPEN ACCESS

Edited by:

Hans-Joachim Anders, Ludwig Maximilian University of

Munich, Germany

Reviewed by:

Sergio Iván Valdés-Ferrer,

Instituto Nacional de Ciencias Médicas y Nutrición Salvador Zubirán

(INCMNSZ), Mexico

Chongxu Shi,

Ludwig Maximilian University of Munich, Germany Joachim Andrassy,

Ludwig Maximilian University of Munich, Germany

${ }^{*}$ Correspondence:

Pierre-Olivier Ludes pierreolivier.ludes@chru-strasbourg.fr

Specialty section:

This article was submitted to Inflammation

a section of the journal

Frontiers in Immunology

Received: 15 September 2020 Accepted: 02 February 2021

Published: 01 March 2021

Citation:

Ludes $P$-O, de Roquetaillade $C$, Chousterman BG, Pottecher $\mathrm{J}$ and Mebazaa A (2021) Role of

Damage-Associated Molecular

Patterns in Septic Acute Kidney Injury,

From Injury to Recovery.

Front. Immunol. 12:606622.

doi: 10.3389/fimmu.2021.606622
Damage-associated molecular patterns (DAMPs) are a group of immunostimulatory molecules, which take part in inflammatory response after tissue injury. Kidney-specific DAMPs include Tamm-Horsfall glycoprotein, crystals, and uromodulin, released by tubular damage for example. Non-kidney-specific DAMPs include intracellular particles such as nucleus [histones, high-mobility group box 1 protein (HMGB1)] and cytosol parts. DAMPs trigger innate immunity by activating the NRLP3 inflammasome, G-protein coupled class receptors or the Toll-like receptor. Tubular necrosis leads to acute kidney injury (AKI) in either septic, ischemic or toxic conditions. Tubular necrosis releases DAMPs such as histones and HMGB1 and increases vascular permeability, which perpetuates shock and hypoperfusion via Toll Like Receptors. In acute tubular necrosis, intracellular abundance of NADPH may explain a chain reaction where necrosis spreads from cell to cell. The nature AKI in intensive care units does not have preclinical models that meet a variation of blood perfusion or a variation of glomerular filtration within hours before catecholamine infusion. However, the dampening of several DAMPs in AKI could provide organ protection. Research should be focused on the numerous pathophysiological pathways to identify the relative contribution to renal dysfunction. The therapeutic perspectives could be strategies to suppress side effect of DAMPs and to promote renal function regeneration.

Keywords: DAMPs, clinical features, precision medicine, kidney recovery, acute kidney injury, sepsis, therapeutic targets

\section{INTRODUCTION}

\section{Damage-Associated Molecular Patterns}

Damage-associated molecular patterns (DAMPs) are endogenous molecules that are released under various conditions of major cell stress or tissue injury. DAMPs are either exposed on the plasma membrane of stressed cells or actively secreted by stressed cells. They can also be passively released into the cellular environment from dying cells after disruption of their plasma membrane or from the damaged extracellular matrix (1). DAMPs also include homeostatic danger signals, which are associated with perturbations of tissue homeostasis (mechanical stress, hypoxia, and scarcity of 
nutrients) and may signal a pathological stress (2). A large variety of DAMPs generated from various sources have been described. Several approaches to classify them have been reported, either according to their cell sub-localization or based on their chemical composition (3,4). A significant body of literature reports on the role of DAMPs in the pathogenesis of acute kidney injury (AKI) and its resolution.

\section{Acute Kidney Injury}

Acute kidney injury is characterized by a rapid decline of renal functions, either glomerular filtration and/or tubular secretion, which leads to an accumulation of metabolic wastes and toxins. AKI can therefore cause distant organ dysfunction, of which, cardiac injury is one the most frequently described (5). The main causes of AKI in clinical settings are sepsis, ischemia-reperfusion injury (IRI), drug-induced nephrotoxicity, and endogenous nephrotoxicity such as rhabdomyolysis. It is estimated that each year two million people die of AKI worldwide and the prevalence has recently increased (6-9). The intensive care unit death rate for AKI is high, ranging from 50 to $80 \%$ and a large proportion (30-70\%) of surviving patients with AKI can develop complications such as chronic kidney disease (CKD) and endstage renal disease, possibly requiring long-term dialysis (10).

Inflammation is one of the main triggers for the onset and worsening of AKI. Additionally, many secondary causes of AKI, such as pathogenic bacteria, toxins, ischemia, traumas, and autoimmune or auto-inflammatory disorders, are related to inflammation (11). Tubular cell damage and death are key factors in AKI which lead to tubular damage, inflammation, and vascular dysfunction. Kidney recovery from AKI is characterized by tubular repair and regeneration $(12,13)$. Loss of renal function due to tubular cell death is associated with the release of DAMPs such as high mobility group box one (HMGB1). These DAMPs stimulate and amplify inflammatory reactions, accelerating tissue damage (14).

In addition to their immediate effects involving innate immunity, DAMPs activate pattern recognition receptors on circulating immune cells. Like their microbial counterparts called pathogen-associated molecular patterns (PAMPs), DAMPs initiate and enhance an immune response by activating toll-like receptors (TLRs) $(15,16)$. Activation of TLRs triggers antigenpresenting cells (APCs) and enhances antigen presentation by dendritic cells and $\mathrm{B}$ cells. Therefore, the mechanism enhances antibody production and promotes kidney diseases such as immune glomerulonephritis immune complex or anti-neutrophil cytoplasmic antibody (ANCA) vasculitis, both of which involve alloimmunity and autoimmunity $(15,17,18)$.

In this review, we will first briefly describe the current knowledge of pathophysiology of septic AKI and the most recent knowledge on the crucial role of inflammation in the process of AKI generation and recovery. We will detail the mechanisms of DAMP generation and release during AKI as well as their role in initiating the immune response and triggering loss of kidney function. Finally, we will discuss recent findings on the role of DAMPs in kidney generation after an insult, and we will discuss findings on the therapeutic perspectives that might emerge by attenuating DAMP signaling.

\section{PATHOPHYSIOLOGY OF SEPTIC AKI}

Pathophysiology of AKI induced by sepsis is an area of intense research. The detailed description has already been reviewed elsewhere (19-21). However, despite decades of intense research, its understanding is still incomplete and constantly evolving. While the hemodynamic nature of AKI has long been the paradigm for sepsis-induced AKI, more recent knowledge has suggested a paradigm shift (22). Although sepsis-induced AKI can demonstrate features of IRI, a key role in acute inflammation and tubular injury has progressively emerged (23-25) with few structural alterations.

\section{Perfusion Alteration \\ Macrocirculation}

Impairment of macrocirculation was initially thought to play a central role in sepsis-induced AKI, as sepsis is most often associated with hemodynamic impairment and shock (26) resulting in impaired kidney perfusion. Still, the evidence to support this hypothesis is very scarce (27), and several animal models of sepsis have revealed that renal blood flow (RBF) was normal or increased during sepsis $(22,28)$. In these models, AKI developed despite normal or increased RBF, which called for a paradigm shift (29). In humans, the strategy to improve oxygen debt have shown no benefit to mortality rates (27) and use of catecholamine to increase oxygen transport has been associated with increased rates of multiple organ failure and death (30). Similarly, observational studies have shown that prior administration of angiotensin-converting enzyme inhibitors (ACEIs) or administration of angiotensin-receptor blockers (ARBs) among patients with septic shock had no impact on the incidence of AKI or death (31). The same has been observed with the administration of non-steroidal anti-inflammatory drugs (NSAIDs) in a prospective randomized controlled trial (32). This, even though these molecules (ACEIs, ARBs, and NSAIDs) are well-known for their strong hemodynamic effect on blood flow from renal arterioles, i.e., the ACEIs and the ARBs reduce glomerular filtration rate and the NSAIDs reduces RBF.

\section{Microvascular and Endothelial Dysfunction}

Microvascular dysfunction is defined as a damage to the microvascular cellular components, including endothelial cells, smooth muscle cells, and the pool of circulating blood cells (33).

The deformability of red blood cells is reduced in septic patients, thus coupled with leukocyte activation, these alterations result in an increase aggregability (33). An increased expression of adhesion molecules for cell-cell interaction has been described on the surface of neutrophils of septic patients. Finally, disseminated intravascular coagulation is often encountered in patients with sepsis and contributes to microcirculatory dysfunction (34).

The progressive systemic hemodynamic imbalance during sepsis causes renal microvascular dysfunction and oxygen homeostasis impairment. The oxygen deficit leads to oxidative stress and hypoxemia. There is a reduction of oxygen in renal tissue impairing the production of ATP, needed for $\mathrm{Na}^{+} / \mathrm{K}^{+}$pump function and $\mathrm{Na}^{+}$reabsorption by the proximal 
tubule (35). The parenchymal cells switch from aerobic to anaerobic respiration producing reactive oxygen species (ROS). In an aerobic state, ROS are produced by the mitochondria resulting in more cell damage and endothelial cell dysfunction (36). Microvascular dysfunction and the oxidative stress have an important role in sepsis-induced AKI. The association of microvascular dysfunction in the kidney with ROS generation has been studied in the murine cecal ligation and puncture (CLP) model of sepsis (37). Wang et al. have shown an early decrease of mean arterial pressure, RBF, and renal capillary perfusion. These alterations were associated with hypoxia and oxidant generation (37).

These microvascular alterations could occur despite normal RBF (38), suggesting heterogenicity in decreased perfusion of the kidney tissue (39). Swelling of endothelial cells is also a common feature of sepsis-induced AKI. Since the kidney is an encapsulated organ, fluid overload, endothelial swelling, and tissue edema could worsen impaired perfusion in the context of sepsis $(40,41)$.

\section{Structural Lesions \\ Cell Death in the Kidney Apoptosis}

Apoptosis or programmed cell death normally releases very few DAMPs. Moreover, uptake of apoptotic debris by phagocytic cells generally triggers a rather anti-inflammatory phenotype (42).

Different pathways can initiate this regulated cell death. In the intrinsic pathway, cellular stress leads to the permeabilization of the mitochondrial outer membrane, resulting in the release of apoptogenic factors, including cytochrome $c$, which then binds Apaf-1 to activate caspase 9 (43). In the extrinsic pathway, ligation of death receptors leads to the recruitment of adapter proteins and the subsequent activation of caspase 8 (44). Stress of the endoplasmic reticulum activates caspase $12(45)$ and caspase 2 may be the initiator of apoptosis (46).

However, under several circumstances, apoptotic cells might amplify the inflammatory response and be responsible for further damage (47). Clearance of apoptotic debris is crucial for kidney repair; it is usually managed by monocytes or macrophages in a process called efferocytosis (42). Lack of efferocytosis has been associated with impaired recovery and kidney fibrosis (48). Histological studies have in fact revealed little tubular cell apoptosis in septic AKI $(22,49,50)$. Conversely, in an experimental model using human tubular epithelial cells in vitro, without hypoperfusion or hypoxia, plasma collected from patients with severe sepsis or septic shock could induce apoptosis and functional alterations in tubular cells and podocytes (51). This observation suggests that mechanisms which trigger apoptosis in the setting of AKI induced by sepsis are soluble in nature.

\section{Regulated Necrosis}

Added to apoptosis, the regulated necrosis (RN) leads to disruption of membrane integrity. The most critical difference between apoptosis and RN probably lies in the release of DAMPs, which stimulates immunogenicity, a process that is absent in apoptosis (52).
Regulated necrosis defines all the genetically encoded pathways of cell death, which result in the rupture of plasma membrane, regardless of the location of the causative trigger, whether it comes from inside (ferroptosis) or outside the cell (necroptosis and pyroptosis). The terms ferroptosis, necroptosis, and pyroptosis refer to defined RN subroutines. Among these pathways of RN, only necroptosis is involved in sepsis-induced AKI (53).

Ferroptosis consists of necrosis by lipid peroxidation. Labile iron is a known risk factor to develop AKI in clinically relevant settings (54). Today, the definition of ferroptosis can be best characterized by a subroutine of $\mathrm{RN}$, which depends on lipid peroxidation, predominantly mediated by polyunsaturated fatty acids (55).

Necroptosis is mediated by a mixed lineage kinase domainlike (MLKL) protein. The activation of MLKL upon its phosphorylation (pMLKL) by the receptor-interacting protein kinase-3 (RIPK3) triggers necroptosis with release of intracellular components (56). MLKL phosphorylation is an essential downstream mediator of necroptosis but not sufficient to cause cell death. Death receptors, such as tumor necrosis factors receptor 1 (TNFR1), and Fas, all belonging to the TNFR superfamily of plasma membrane receptors, may mediate necroptosis (57). Sureshbabu et al. (53) have demonstrated that in mice with polymicrobial septic condition, the RIPK3 promotes sepsis-induced AKI and aggravates kidney tubular injury independently of the classical MLKL-dependent necroptosis pathways (Figure 1). They also observed elevated urinary and plasma RIPK3 levels in patients with sepsis-induced AKI.

Pyroptosis is mediated by gasdermin D, which is cleaved by caspase as well as pro-interleukin-1bêta and pro-interleukin18. The plasma membrane phosphatidylinositol 4,5-biphosphate (PIP2) is targeted by gasdermin D. Subsequently, membrane extrusion is overwhelming, resulting in extensive bleeding and rupture of the membrane when a critical concentration of PIP2-bound gasdermin D has accumulated at the plasma membrane (58).

\section{Tubular Injury}

Tubular injury is crucial in sepsis-induced AKI pathophysiology. Tubular cells are prone to microcirculation impairment and inflammation, which makes them particularly vulnerable to sepsis (59). However, in humans, pathological studies have in fact revealed little tubular apoptosis lesions, suggesting that those cells are able to inhibit the processes leading to apoptosis. These cells are able to downregulate their metabolism (60) or undergo cell cycle arrest (61) in order to limit damage and allow repair. Lack of reprogramming after such adaptive response was also linked to subsequent kidney fibrosis and CKD $(60,61)$.

\section{Inflammation and Cytokine Storm}

Several teams have shown a strong association between the levels of cytokines such as interleukins (IL), especially IL-6 and IL-10, or migration-inhibition factors and the development of sepsisinduced AKI (62). Adhesion and infiltration of leukocytes into kidney tissue appear to be detrimental for kidney function and leads to AKI (63). 


\section{SEPSIS}

KIDNEY INJURY / FIBROSIS

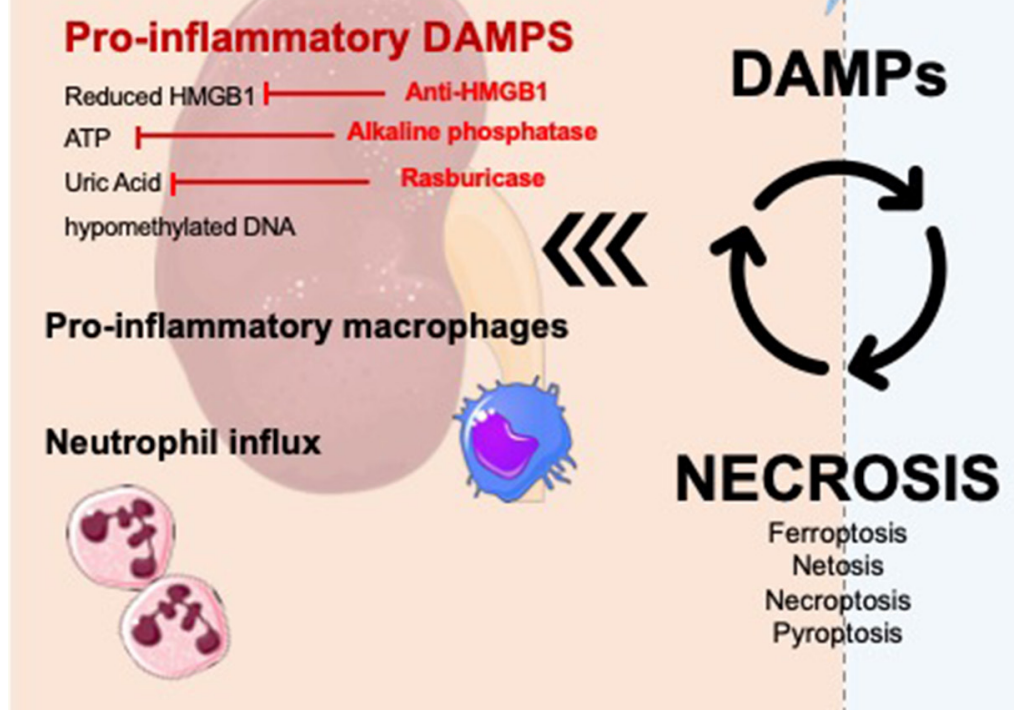

KIDNEY REPAIR / TUBULE REGENERATION

4

TLR2 agonists

lipoteichoic acid zymozan

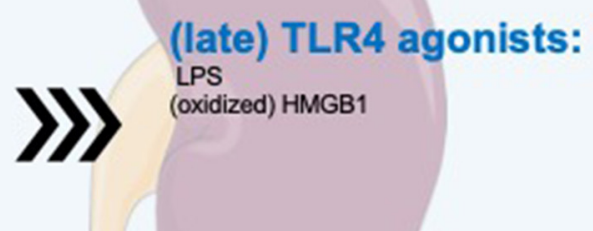

M2 macrophage polarization Tamm-Horsfall Protein

NETs Adenosine

FIGURE 1 | DAMPs in sepsis-induced acute kidney injury and therapeutic perspectives. DAMPs are secreted during sepsis-AKI and enhance kidney injury and kidney fibrosis. The secretion of DAMPs is the result of different mechanisms of necrosis (ferroptosis, necroptosis, pyroptosis, NETosis). Apoptosis leads to very few DAMPs. DAMPs promote immune response and recruit immune cells such as neutrophils to infiltrate the tissue. DAMPs also play a role in tubular regeneration and in restoring kidney function by macrophage polarization and interaction with TLR2/TLR4. The inhibition of specific DAMPs by anti-HMGB1, alkaline phosphatase or Rasburicase could prevent progression of renal dysfunction.

Recent experimental data as well as previous histological studies have highlighted the importance of leukocyte recruitment and inflammation as a central actor of sepsis-induced AKI (64). Histological studies revealed that unlike renal IRI, which is characterized by apoptosis or necrosis of tubular epithelial cells, sepsis-induced AKI was characterized by healthy or reversible tubular epithelial cell injury, and occasional necrosis $(20,49)$. These observations corresponded to a rather conserved architecture with few post-anoxic tubular lesions. These studies have also demonstrated a very strong infiltration of leukocytes, mainly monocytic cells, in the kidney tissue during sepsis (49).

In fact, sepsis is a clinical syndrome characterized by systemic inflammation caused by an infective agent. This process tends to expand and cause multiple organ failure. In particular, AKI results primarily from soluble factors released into the circulation (65). This first event is triggered by cytokines and the massive release of DAMPs and PAMPs into circulation. These DAMPs and PAMPs later trigger and accentuate systemic inflammation (66). Although sublethal injury may be reversible, the death of tubular cells triggers a release of DAMPs which could in turn, amplify inflammation (14). This cascade is called necroinflammation and produces a downward cascade after the primary damage and participates in kidney failure with immune cell infiltration (67). Several studies have pointed out that the level of DAMPs was correlated with survival during sepsis $(68,69)$.
Damage-associated molecular patterns are central effectors at all levels in the pathophysiology of sepsis-induced AKI. As the propagation medium for inflammation, they contribute to macro/microvascular impairment, endothelial dysfunction, leukocyte recruitment, and tubular injury. This is because they are also capable of perpetuating injury long after the clearance of the bacterial pathogens. In their study on non-human primates, Sursal et al. (70) demonstrated that, conversely to PAMPs (assessed by measurement of circulating bacterial 16SDNA) which were rapidly cleared, the generation of DAMPs (assessed by the measurement of circulating mitochondrial DNA (mtDNA) continued long after the onset of symptoms. Such observations suggest a central role of DAMPs in the generation and maintenance of systemic inflammatory response syndrome during sepsis $(70,71)$.

Taken together, those observations highlight the central role of inflammation and leukocyte infiltration in the pathophysiology of AKI during sepsis $(62,72)$. With their DANGER signal function, DAMPs could play a central role in the process of septic AKI.

\section{ORIGIN OF DAMPS IN SEPTIC AKI}

Several DAMPs involved in septic AKI are listed in Table $\mathbf{1}$ with their location and related reference. 
TABLE 1 | Type of DAMPs in septic AKI.

\begin{tabular}{llllc}
\hline & Location & Name & Interaction & References \\
\hline $\begin{array}{llll}\text { Kidney, } \\
\text { non-specific }\end{array}$ & Nucleus & HMGB1 & TLR2/TLR4 & $(73)$ \\
& & & CXCL12 & $(74)$ \\
& & & $(76)$ \\
& & Histones & TLR2/TLR4 & $(80)$ \\
& & & $(81)$ \\
& & & $(82)$ \\
& Mitochondrial & mtDNA & TLR9 & $(90)$ \\
& Extracellular & Decorin & TLR2/TLR4 & $(87)$ \\
& & Biglycan & TLR2/TLR4 & $(83)$ \\
& & P2X receptor & $(84)$ \\
& & & $(85)$ \\
Kidney, & & & $(86)$ \\
specific & & & & $(92)$ \\
\hline
\end{tabular}

Several DAMPs (Damage associated molecular patterns) of interest which promote sepsis acute kidney injury and relevant reference. HMGB1, High mobility group box 1; TLR, Toll-like receptor; $m t D N A$, mitochondrial DNA.

\section{Non-kidney Specific DAMPs High Mobility Group Box One}

High mobility group box one is an intranuclear protein involved in sepsis and AKI. Once released from stromal or immune cells, it can interact with a variety of cell surface receptors, such as TLR2 and TLR4, leading to various functions. The proinflammatory properties of HMGB1 are by far the most described (73).

High mobility group box one can amplify inflammation by positive feedback during sepsis-induced AKI. HMGB1 is known to be a late-appearing inflammatory cytokine during sepsis. However, when a septic episode complicates a long-lasting chronic kidney disease, HMGB1 is an early appearing cytokine measured in the plasma within $6 \mathrm{~h}$ in mice with septic condition due to CLP (74). Observations in the AKI septic mouse model suggest that the renal clearance of HMGB1 is reduced in CKD and that a small release of HMGB1 is enough to induce a significant increase in its plasma concentration. The timing of HMGB1 release therefore depends on the extent of kidney failure predominant at the onset of sepsis (74).

However, it has also been shown that this DAMP could also drive regulatory functions. HMGB1 is a redox sensitive DAMP, containing three cysteines which subject this molecule to redox reactions (75). Depending on the level of oxidation, three isoforms of HMGB1 can coexist at different levels and can trigger different types of immune reactions. Fully reduced HMGB1 ligate with the chemokine CXCL12 which further binds to CXCR4 receptor (76). Conversely, Kazama et al. demonstrated in a mouse model that terminal oxidation of HMGB1, which can be induced by the production of ROS by mitochondria, is sufficient and necessary to inactivate the immunostimulatory effects of HMGB1. The terminal oxidation of HMGB1 may confer to HMGB1 some tolerogenic properties, lowering immune activation following apoptosis (77).

Indeed, while HMGB1 was long believed to be trapped inside the nucleus during apoptosis, it has been shown that oxidized HMGB1 is easily released from the apoptotic cells (77) and triggers tolerance (78). In addition, macrophages can actively release HMGB1 after phagocytosis of apoptotic debris (79), challenging the concept of apoptosis as "the silent death."

\section{Histones}

Similar to HMGB1, histones are intracellular and intranuclear proteins, which participate in the compaction of DNA. In addition to their physiological role in homeostatic situations, histones also behave like DAMPs, activating TLR2/TLR4, and inducing local and systemic inflammation $(80,81)$.

$\mathrm{Xu}$ et al. (82) detected histones in the circulation of baboons infected with Escherichia coli, and increased histone levels accompanied the development of renal dysfunction. Moreover, these authors have shown that the anti-histone antibody reduced the mortality of mice in lipopolysaccharide (LPS), TNF, and CLP models of sepsis (82).

\section{Biglycan}

Biglycan is an extracellular DAMP involved in acute ischemic kidney injury and septic AKI, which activates the NRLP3 inflammasome via TLR2/TLR4 and P2X receptors (83-85).

Schaefer et al. (85) demonstrated that at the early stage of sepsis induced by LPS and zymosan, the level of TNF-alpha (TNF- $\alpha$ ) in serum was considerably lower in biglycan-deficient mice than in wild-type mice. Previously, they observed an overexpression of biglycan and an increase in the number of infiltrating cells in a model of renal inflammation (86).

\section{Decorin}

Decorin is an extracellular DAMP involved in septic AKI, which activates TLR2/TLR4 (87). Merline et al. measured circulating decorin in plasma samples from a cohort of patients with septic Gram-negative or Gram-positive infections. Immunoblot and ELISA analysis revealed increased levels of decorin protein core in patients with sepsis compared to healthy individuals. The authors experimentally induced sepsis with LPS in decorinknockout mice, and they showed that the localization of decorin was in close proximity to macrophage in the lungs. In addition, peritoneal macrophages showed enhanced expression of decorin mRNA as well as increased decorin secretion $30 \mathrm{~min}$ after LPS stimulation. Nevertheless, the secretion of decorin by renal macrophages should be further demonstrated.

\section{Extracellular DNA}

Extracellular DNA is a DAMP involved in renal IRI. Necrotic cell-derived DNA leads to platelet activation, platelet-granulocyte interaction, and then neutrophil extracellular trap formation, resulting in renal inflammation and an increase in renal injury (88).

Shi et al. (89) have shown a mouse model of cholesterol crystal (CC) embolism by injection of CC into the kidney artery. The extracellular DNA is involved in CC embolism condition. The arterial obstruction and the organ failure caused by CC embolism is associated with neutrophil extracellular trap formation and DNA release mainly from kidney endothelial cells (89).

More specifically, Tsuji et al. (90) have demonstrated the role of mtDNA in TLR9-associated septic AKI. Their findings on a CLP model of sepsis in wild-type and TLR9-knockout mice 
suggest that mtDNA activates TLR9 and contributes to cytokine production and kidney injury during polymicrobial sepsis.

\section{Kidney Specific DAMPs Uromodulin}

Uromodulin, also known as Tamm-Horsfall protein, is secreted at the thick ascending limb of the distal tubule. It is an adhesive particle-forming protein, which coats many elements in the distal tubule: cell casts, granular casts (by coating cell debris), and crystal aggregation. The coating of bacteria and inflammatory cytokines also promotes their elimination (91). Inside the tubular lumen, uromodulin is immunologically inactive. However, during tubular injury, uromodulin leaks into the interstitial compartment and becomes a DAMP by activating the interstitial dendritic cells via TLR4 (92). In dendritic cells, the NLRP3 inflammasome is activated by phagocytosis and endosomal destabilization in response to the presence of uromodulin in the interstitium. The innate immunity during tubular injury is ultimately activated by the release of IL-1 $\beta$ (93).

\section{ROLES OF DAMPS IN KIDNEY INJURY AND INFLAMMATION}

Some studies have shown evidence that microbial proinflammatory agents are among the strongest trigger of inflammation. However, many types of sterile stimuli, including trauma, ischemia, stress, and environmental factors, trigger pathogen-free state of inflammation called "sterile inflammation" (94).

Acute tissue injury triggers a rapid influx of neutrophils. This is followed by increased adhesion of circulating monocyte to activate endothelial surfaces and their subsequent extravasation into interstitial compartments (95). Damaged cells released DAMPs such as HMGB1, ATP, uric acid, or hypomethylated DNA $(96,97)$. In these tissues, the proinflammatory phenotype of macrophages promotes the secretion of cytokines, chemokines, ROS, and other proinflammatory mediators (98). Proinflammatory macrophages release matrix metalloproteases to enable their migration through basement membranes and interstitial extracellular matrix networks. The resulting small extracellular matrix peptides can function as immunostimulatory DAMPs via TLRs and maintain the proinflammatory state (99).

The sterile kidney suffers mainly from infiltrates of proinflammatory macrophages. For example, proinflammatory macrophages release large amounts of TNF- $\alpha$ (100). The link between inflammation and the promotion of kidney injury in sepsis has not been adequately explained. Inhibition of the mechanism of inflammation, such as leucocyte adhesion and infiltration into kidney improves kidney function in sepsisinduced AKI (101). Moreover, in mice with septis-induced AKI, the inhibition of inflammatory cytokines and oxidative stress in dendritic cells and neutrophils improve kidney function (102).

\section{ROLES OF DAMPS IN KIDNEY REGENERATION AND RECOVERY}

Recent data suggest that DAMPs may promote tubule regeneration upon injury and not only to potentiate kidney injury and inflammation (103).

Septic condition leads to inflammation which increases kidney failure and worsens tissue damage; therefore, more necrotic cell parts are released $(12,104)$. For example, mice lacking HMGB1 are protected from post-ischemic acute renal failure because tubular cell necrosis no longer triggers post-ischemic renal inflammation and tubular damage (105). Nevertheless, recent studies highlighted the role of DAMPs signaling the regeneration post-AKI $(106,107)$.

\section{Molecular Mechanisms Leading Recovery From AKI}

Recovery from acute tubular injury is not completely understood. This process involves recruitment and repolarization of leukocytes, which are an important source of paracrine growth and signaling factor. The recovery from AKI involves, as a predominant mechanism, an hypertrophy of remnant tubular cells via endocycle (108) which is a common cell cycle variant where cells successively duplicate genomic DNA without segregating their chromosome during mitosis (109). The recovery driven by the proliferation and differentiation of progenitor cells appears limited $(108,110)$. Failure of any of those processes could lead to inadequate repair which could, over time, lead to the development of CKD. Understanding mechanisms leading to AKI-CKD progression is important in order to identify potential therapeutic targets. Therefore, in this process, more attention is paid to the role of DAMPs and their receptors.

\section{Role of DAMPs in Monocyte/Macrophages Polarization}

During the injury phase, DAMPs and other cytokines prime the M0 monocyte entering a proinflammatory M1 phenotype which contributes to tissue inflammation and perpetuates tissue damage (111). Over time, monocytes evolve toward an antiinflammatory, M2 phenotype (111). Depletion of macrophages and dendritic cells in the recovery phase is responsible for delayed recovery $(112,113)$, thus the M1-M2 shift appears to be vital for wound healing and kidney regeneration, promoting tubular cell proliferation and functional recovery $(114,115)$. The mechanisms leading to the M1-M2 transition are not fully understood but could involve DAMP signaling. Neutrophil extracellular traps (NETs) for example, are thought to induce M2 phenotype (106) while adenosine promotes the shift to anti-inflammatory and angiogenic M2 macrophages by binding to adenosine A2 receptors (Figure 1) (107). In a recent study, Micanovic and colleagues found that the basolateral secreted Tamm-Horsfall protein could trigger M2 macrophage polarization and attenuate inflammation. In their study, $\mathrm{THP}^{-/-}$ mice demonstrated aggravated injury and an impaired transition of renal macrophages to M2 phenotype following IRI (116). However, no study to date specifically addressed the role 
of DAMP signaling in macrophage M2 polarization during septic AKI.

\section{Pattern Recognition Receptor}

The innate immune system is an important modulator of the inflammatory response during infection and tissue repair. It provides the first line of host defense initiated by several classes of pattern recognition receptors, such as membrane TLRs (117).

\section{Agonists of TLR2}

Renal progenitor cells (RPCs) have a controversial role in the process of kidney function recovery. Maeshima et al. explored the role of these cells and their involvement in "tubular regeneration concept" after injury. RPCs represent tubular committed progenitors that display resistance to apoptotic stimuli and exert regenerative potential for injured tubular tissue (118). Sallustio et al. (119) have suggested that following insult, TLR2 agonists DAMPs (lipoteichoic acid or zymosan) may induce RPC differentiation and accelerate tubule regeneration (Figure 1). Following the same idea, several studies have reported the use of marrow stromal cells to partially protect the kidney from injury $(120,121)$. However, the exact role of TLR2 agonists on kidney repair in the context of sepsis remains to be investigated.

The tubular regeneration concept is ruled out by Lazzeri et al. (108). They found that only a few tubular epithelial cells undergo mitosis and contributes to kidney regeneration. Their results indicate that new tubular cells arise exclusively from pre-existing cells that expand, regenerating the entire S3 or distal tubule segment, and therefore behave as progenitor cells.

\section{Agonists of TLR4}

The role of TLR4 driven signaling in kidney regeneration was recently demonstrated. In an in vitro model of IRI, Kulkarni et al. (122) showed that following injury, TLR4-mediated stimulation could induce the release of IL-22 from APCs (dendritic cells and macrophages), which in turn stimulate kidney regeneration. IL-22 is a newly discovered cytokine of the IL-10 superfamily (123) and its involvement in kidney injury and regeneration remains to be studied. Indeed, the exact contribution of IL-22 signaling in the context of septic AKI remains unclear. In a model of peritoneal sepsis, Weber and colleagues demonstrated that blocking IL-22 resulted in reduced organ damage and bacterial load (124). Such a divergence could be explained by different timing of stimulation by IL-22. Indeed, TLR4-mediated stimulation has long be known to play a role in promoting kidney injury during the acute phase (125). Recent reporting has shown that its blockage during the recovery phase can delay tubular recovery (Figure 1) (122). The exact mechanisms by which TLR4 signaling can either mediate inflammation or healing, depending on the timeline, remains to be elucidated.

\section{THERAPEUTIC PERSPECTIVES}

Damage-associated molecular patterns can promote and worsen $\mathrm{AKI}$ and are involved in the regeneration of renal tissue injury.
The modulation of DAMP signaling pathways to control the immune response, as presented in Figure 1, is a field of research.

\section{Anti-HMGB1}

Since extracellular HMGB1 was identified as a late proinflammatory mediator during sepsis, several studies have focused on modulating its signal to decrease sepsisassociated inflammation $(126,127)$. In vivo models of sepsis have demonstrated that HMGB1 could be found $8 \mathrm{~h}$ after the onset of sepsis with a peak occurring between 16 and $32 \mathrm{~h}$ (128). In a CLP model of sepsis, mice treated with anti-HMGB1 antibody had a significantly lower mortality than mice undergoing CLP alone (129). More importantly, this study demonstrated that late administration of anti-HMGB1 antibodies was able to treat mice with clinical signs of shock, which makes this strategy very interesting in the treatment of human sepsis. Several studies have shown that therapeutic intervention aimed at targeting inflammation induced by HMGB1 could improve survival in animal models $(130,131)$; however, no study has specifically addressed the potential interest of such an approach in reducing kidney inflammation and the incidence of AKI during sepsis. Still, while anti-HMGB1 therapy has been successful in various clinical conditions, the translation of these promising findings into the clinical field remains to be done.

\section{Alkaline Phosphatase}

Alkaline phosphatase also shows some therapeutic promise in the treatment of sepsis-associated AKI. Alkaline phosphatase is an endogenous enzyme that exerts detoxifying effects by dephosphorylation of both extracellular ATP (132) and endotoxin (133). Recombinant alkaline phosphatase demonstrated its benefit in the preclinical phase (134); however, in a randomized controlled trial enrolling 301 patients, treatment with recombinant alkaline phosphatase did not significantly improve kidney function in the short term (135). More research is needed to clarify the benefits of alkaline phosphatase on other clinical outcomes but also on long-term kidney recovery.

\section{Rasburicase}

Targeting uric acid generation could be of particular interest in the treatment of sepsis-induced AKI.

The mechanisms of uric acid increase in sepsis are unknown and could be due to either increased production or decreased excretion. Severe sepsis may induce ischemia or hypoxia in multiple organs including the kidney and may activate xanthine oxidase in the endothelium to produce uric acid (136).

In fact, under physiological conditions, the majority of uric acid $(2 / 3)$ is excreted with the urine, while the other third is excreted via the intestinal route. Therefore, the release of uric acid could trigger an inflammatory response and worsen kidney injury. In turn, AKI with reduced urine output could increase the flow of uric acid due to lack of urinary excretion (137). Several studies have linked increased plasma uric acid and poor prognosis and reported an increased risk for AKI among patients with elevated uric acid $(136,138)$. However, in another study using multivariate analysis, such association was no longer significant (139). Uric acid can cause AKI due to a variety of 
mechanisms ranging from direct tubular toxicity and crystal induced nephropathy to indirect injury secondary to the release of vasoactive mediators and oxidative stress (136). From this perspective, therapy aimed at lowering uric acid during sepsis could be of interest.

\section{CONCLUSIONS}

In this review, we aimed to highlight a limited number of recognized DAMPs. We have described the crucial role of these DAMPs in septic AKI as initiating and then amplifying the pathophysiological inflammatory process. Moreover, we stressed the most recent insights in AKI recovery.

In fact, any misplaced or abnormal metabolite level can be a DAMP, and sophisticated analysis studies can reveal the full profile of the DAMPs in numerous conditions included sepsisinduced AKI. Following a major stress, a therapeutic perspective that might emerge is dampening the signaling of DAMPs. This kind of intervention could certainly not be as effective as avoiding the generation of DAMPs. Another objective should be the elimination of the inflammatory agent (140).

\section{REFERENCES}

1. Rubartelli A, Lotze MT. Inside, outside, upside down: damage-associated molecular-pattern molecules (DAMPs) and redox. Trends Immunol. (2007) 28:429-36. doi: 10.1016/j.it.2007.08.004

2. Gallo PM, Gallucci S. The dendritic cell response to classic, emerging, and homeostatic danger signals. implications for autoimmunity. Front Immunol. (2013) 4:138. doi: 10.3389/fimmu.2013.00138

3. Garg AD, Galluzzi L, Apetoh L, Baert T, Birge RB, Bravo-San Pedro JM, et al. molecular and translational classifications of DAMPs in immunogenic cell death. Front Immunol. (2015) 6:588. doi: 10.3389/fimmu.2015.00588

4. Land WG, Agostinis P, Gasser S, Garg AD, Linkermann A. Transplantation and damage-associated molecular patterns (DAMPs). Am J Transplant. (2016) 16:3338-61. doi: 10.1111/ajt.13963

5. Yap SC, Lee HT, Warner DS. Acute kidney injury and extrarenal organ dysfunction new concepts and experimental evidence. Anesthesiology. (2012) 116:1139-48. doi: 10.1097/ALN.0b013e31824f951b

6. Mehta RL, Burdmann EA, Cerdá J, Feehally J, Finkelstein F, GarcíaGarcía G, et al. Recognition and management of acute kidney injury in the International Society of Nephrology 0by25 Global Snapshot: a multinational cross-sectional study. Lancet. (2016) 387:2017-25. doi: 10.1016/S0140-6736(16)30240-9

7. Bouchard J, Mehta RL. Acute kidney injury in western countries. Kidney Dis. (2016) 2:103-10. doi: 10.1159/000445091

8. Hsu RK, McCulloch CE, Dudley RA, Lo LJ, Hsu C. Temporal changes in incidence of dialysis-requiring AKI. J Am Soc Nephrol. (2012) 24:37-42. doi: 10.1681/ASN.2012080800

9. Lameire NH, Bagga A, Cruz D, De Maeseneer J, Endre Z, Kellum JA, et al. Acute kidney injury: an increasing global concern. Lancet. (2013) 382:170-9. doi: 10.1016/S0140-6736(13)60647-9

10. Heung M, Faubel S, Watnick S, Cruz DN, Koyner JL, Mour G, et al. Outpatient dialysis for patients with AKI: a policy approach to improving care. Clin J Am Soc Nephrol. (2015) 10:1868-74. doi: 10.2215/CJN.02290215

11. Matzinger P. Tolerance, danger, and the extended family. Annu Rev Immunol. (1994) 12:991-1045. doi: 10.1146/annurev.iy.12.040194.005015

12. Bonventre JV, Yang L. Cellular pathophysiology of ischemic acute kidney injury. J Clin Invest. (2011) 121:4210-21. doi: 10.1172/JCI45161

13. Zarjou A, Agarwal A. Sepsis and acute kidney injury. J Am Soc Nephrol. (2011) 22:999-1006. doi: 10.1681/ASN.2010050484

\section{AUTHOR CONTRIBUTIONS}

P-OL, CdR, BGC, JP, and AM conceived of the presented manuscript. All authors discussed the findings and contributed to the final manuscript.

\section{FUNDING}

The publications fees are funded by Hôpitaux Universitaires Strasbourg, Direction de la Recherche Clinique et des Innovations, Strasbourg, France.

\section{ACKNOWLEDGMENTS}

The authors thank Jo-Ann Elicia West, M.Sc., an independent publication consultant in Cartigny L'Epinay, France, for providing editorial support, which was funded by Hôpitaux Universitaires Strasbourg, Direction de la Recherche Clinique et des Innovations, Strasbourg, France in accordance with Good Publication Practice (GPP3) guidelines (http://www.ismpp.org/gpp3).

14. Ratliff BB, Rabadi MM, Vasko R, Yasuda K, Goligorsky MS. Messengers without borders: mediators of systemic inflammatory response in AKI. J Am Soc Nephrol. (2013) 24:529-36. doi: 10.1681/ASN.2012060633

15. Marshak-Rothstein A, Rifkin IR. Immunologically active autoantigens: the role of toll-like receptors in the development of chronic inflammatory disease. Annu Rev Immunol. (2007) 25:419-41. doi: 10.1146/annurev.immunol.22.012703.104514

16. Waldner $H$. The role of innate immune responses in autoimmune disease development. Autoimmun Rev. (2009) 8:400-4. doi: 10.1016/j.autrev.2008.12.019

17. Rock KL, Latz E, Ontiveros F, Kono H. The sterile inflammatory response. Annu Rev Immunol. (2010) 28:321-42. doi: 10.1146/annurev-immunol-030409-101311

18. Anders H-J, Banas B, Schlöndorff D. Signaling danger: toll-like receptors and their potential roles in kidney disease. J Am Soc Nephrol. (2004) 15:854-67. doi: 10.1097/01.ASN.0000121781.89599.16

19. Zarbock A, Gomez H, Kellum JA. Sepsis-induced AKI revisited: pathophysiology, prevention and future therapies. Curr Opin Crit Care. (2014) 20:588-95. doi: 10.1097/MCC.0000000000000153

20. Takasu O, Gaut JP, Watanabe E, To K, Fagley RE, Sato B, et al. Mechanisms of cardiac and renal dysfunction in patients dying of sepsis. Am J Respir Crit Care Med. (2013) 187:509-17. doi: 10.1164/rccm.201211-1983OC

21. Gomez H, Ince C, De Backer D, Pickkers P, Payen D, Hotchkiss $\mathrm{J}$, et al. A Unified theory of sepsis-induced acute kidney injury: inflammation, microcirculatory dysfunction, bioenergetics and the tubular cell adaptation to injury. Shock Augusta Ga. (2014) 41:3-11. doi: 10.1097/SHK.0000000000000052

22. Maiden MJ, Otto S, Brealey JK, Finnis ME, Chapman MJ, Kuchel TR, et al. Structure and function of the kidney in septic shock. A prospective controlled experimental study. Am J Respir Crit Care Med. (2016) 194:692700. doi: 10.1164/rccm.201511-2285OC

23. Fani F, Regolisti G, Delsante M, Cantaluppi V, Castellano G, Gesualdo L, et al. Recent advances in the pathogenetic mechanisms of sepsis-associated acute kidney injury. J Nephrol. (2018) 31:351-9. doi: 10.1007/s40620-017-0452-4

24. Bellomo R, Kellum JA, Ronco C, Wald R, Martensson J, Maiden M, et al. Acute kidney injury in sepsis. Intensive Care Med. (2017) 43:816-28. doi: 10.1007/s00134-017-4755-7

25. Dellepiane S, Marengo M, Cantaluppi V. Detrimental cross-talk between sepsis and acute kidney injury: new pathogenic mechanisms, 
early biomarkers and targeted therapies. Crit Care. (2016) 20:61. doi: 10.1186/s13054-016-1219-3

26. Schrier RW, Abebe KZ, Perrone RD, Torres VE, Braun WE, Steinman TI, et al. Blood pressure in early autosomal dominant polycystic kidney disease. N Engl J Med. (2014) 371:2255-66. doi: 10.1056/NEJMoa14 02685

27. Prowle JR, Ishikawa K, May CN, Bellomo R. Renal blood flow during acute renal failure in man. Blood Purif. (2009) 28:216-25. doi: 10.1159/000230813

28. Di Giantomasso D, May CN, Bellomo R. Vital organ blood flow during hyperdynamic sepsis. Chest. (2003) 124:1053-9. doi: 10.1378/chest.124.3.1053

29. Chvojka J, Sykora R, Krouzecky A, Radej J, Varnerova V, Karvunidis T, et al. Renal haemodynamic, microcirculatory, metabolic and histopathological responses to peritonitis-induced septic shock in pigs. Crit Care Lond Engl. (2008) 12:R164. doi: 10.1186/cc7164

30. Hayes MA, Timmins AC, Yau EH, Palazzo M, Hinds CJ, Watson D. Elevation of systemic oxygen delivery in the treatment of critically ill patients. N Engl J Med. (1994) 330:1717-22. doi: 10.1056/NEJM1994061633 02404

31. de Roquetaillade C, Jamme M, Charpentier J, Chiche J-D, Cariou A, Mira J-P, et al. Hemodynamic impact of cardiovascular antihypertensive medications in patients with sepsis-related acute circulatory failure. Shock Augusta Ga. (2020) 54:315-20. doi: 10.1097/SHK.0000000000001524

32. Bernard GR, Wheeler AP, Russell JA, Schein R, Summer WR, Steinberg KP, et al. The effects of ibuprofen on the physiology and survival of patients with sepsis. The Ibuprofen in Sepsis Study Group. N Engl J Med. (1997) 336:912-8. doi: 10.1056/NEJM199703273361303

33. Lehr H-A, Bittinger F, Kirkpatrick CJ. Microcirculatory dysfunction in sepsis: a pathogenetic basis for therapy? J Pathol. (2000) 190:373-86. doi: 10.1002/(SICI)1096-9896(200002)190:3<373::AID-PATH593>3.0.CO;2-3

34. Christ F, Gamble J, Gartside IB, Kox WJ. Increased microvascular water permeability in patients with septic shock, assessed with venous congestion plethysmography (VCP). Intensive Care Med. (1998) 24:18-27. doi: $10.1007 / \mathrm{s} 001340050509$

35. Evans RG, Ince C, Joles JA, Smith DW, May CN, O'Connor PM, et al. Haemodynamic influences on kidney oxygenation: clinical implications of integrative physiology. Clin Exp Pharmacol Physiol. (2013) 40:106-22. doi: 10.1111/1440-1681.12031

36. Exline MC, Crouser ED. Mitochondrial mechanisms of sepsis-induced organ failure. Front Biosci J Virtual Libr. (2008) 13:5030-41.

37. Wang Z, Holthoff JH, Seely KA, Pathak E, Spencer HJ, Gokden N, et al. Development of oxidative stress in the peritubular capillary microenvironment mediates sepsis-induced renal microcirculatory failure and acute kidney injury. Am J Pathol. (2012) 180:505-16. doi: 10.1016/j.ajpath.2011.10.011

38. Bezemer R, Legrand M, Klijn E, Heger M, Post ICJH, Gulik TM van, et al. Real-time assessment of renal cortical microvascular perfusion heterogeneities using near-infrared laser speckle imaging. Opt Express. (2010) 18:15054-61. doi: 10.1364/OE.18.015054

39. Yan R, van Meurs M, Popa ER, Li R, Zwiers PJ, Zijlstra JG, et al. Early heterogenic response of renal microvasculature to hemorrhagic shock/resuscitation and the influence of NF- $\mathrm{kB}$ pathway blockade. Shock Augusta Ga. (2019) 51:200-12. doi: 10.1097/SHK.0000000000001126

40. Legrand M, Dupuis C, Simon C, Gayat E, Mateo J, Lukaszewicz A-C, et al. Association between systemic hemodynamics and septic acute kidney injury in critically ill patients: a retrospective observational study. Crit Care. (2013) 17:R278. doi: 10.1186/cc13133

41. Prowle JR, Kirwan CJ, Bellomo R. Fluid management for the prevention and attenuation of acute kidney injury. Nat Rev Nephrol. (2014) 10:37-47. doi: $10.1038 /$ nrneph.2013.232

42. Zhang S, Weinberg S, DeBerge M, Gainullina A, Schipma M, Kinchen JM, et al. Efferocytosis fuels requirements of fatty acid oxidation and the electron transport chain to polarize macrophages for tissue repair. Cell Metab. (2019) 29:443-56.e5. doi: 10.1016/j.cmet.2018.12.004

43. Franklin EE, Robertson JD. Requirement of Apaf-1 for mitochondrial events and the cleavage or activation of all procaspases during genotoxic stress-induced apoptosis. Biochem J. (2007) 405(Pt 1):115-22. doi: 10.1042/BJ20061576
44. Ashkenazi A, Dixit VM. Death receptors: signaling and modulation. Science. (1998) 281:1305-8. doi: 10.1126/science.281.5381.1305

45. Nakagawa T, Zhu H, Morishima N, Li E, Xu J, Yankner BA, et al. Caspase12 mediates endoplasmic-reticulum-specific apoptosis and cytotoxicity by amyloid- $\beta$. Nature. (2000) 403:98-103. doi: 10.1038/47513

46. Lassus P, Opitz-Araya X, Lazebnik Y. Requirement for Caspase-2 in stressinduced apoptosis before mitochondrial permeabilization. Science. (2002) 297:1352-4. doi: 10.1126/science.1074721

47. Huebener P, Pradere J-P, Hernandez C, Gwak G-Y, Caviglia JM, Mu X, et al. The HMGB1/RAGE axis triggers neutrophil-mediated injury amplification following necrosis. Clin Invest. (2015) 125:539-50 doi: 10.1172/JCI76887

48. Morioka S, Maueröder C, Ravichandran KS. Living on the edge: efferocytosis at the interface of homeostasis and pathology. Immunity. (2019) 50:1149-62. doi: 10.1016/j.immuni.2019.04.018

49. Lerolle N, Nochy D, Guérot E, Bruneval P, Fagon J-Y, Diehl J-L, et al. Histopathology of septic shock induced acute kidney injury: apoptosis and leukocytic infiltration. Intensive Care Med. (2010) 36:471-8. doi: $10.1007 / \mathrm{s} 00134-009-1723-\mathrm{x}$

50. Kosaka J, Lankadeva YR, May CN, Bellomo R. Histopathology of septic acute kidney injury: a systematic review of experimental data. Crit Care Med. (2016) 44:e897-903. doi: 10.1097/CCM.0000000000001735

51. Mariano F, Cantaluppi V, Stella M, Romanazzi GM, Assenzio B, Cairo M, et al. Circulating plasma factors induce tubular and glomerular alterations in septic burns patients. Crit Care. (2008) 12:R42. doi: 10.1186/cc6848

52. Sarhan M, von Mässenhausen A, Hugo C, Oberbauer R, Linkermann A. Immunological consequences of kidney cell death. Cell Death Dis. (2018) 9:114. doi: 10.1038/s41419-017-0057-9

53. Sureshbabu A, Patino E, Ma KC, Laursen K, Finkelsztein EJ, Akchurin O, et al. RIPK3 promotes sepsis-induced acute kidney injury via mitochondrial dysfunction. JCI Insight. (2018) 3:e98411. doi: 10.1172/jci.insight.98411

54. Leaf DE, Rajapurkar M, Lele SS, Mukhopadhyay B, Rawn JD, Frendl G, et al. Increased plasma catalytic iron in patients may mediate acute kidney injury and death following cardiac surgery. Kidney Int. (2015) 87:1046-54. doi: 10.1038/ki.2014.374

55. Yang WS, Stockwell BR. Ferroptosis: death by lipid peroxidation. Trends Cell Biol. (2016) 26:165-76. doi: 10.1016/j.tcb.2015.10.014

56. Yoon S, Kovalenko A, Bogdanov K, Wallach D. MLKL, the protein that mediates necroptosis, also regulates endosomal trafficking and extracellular vesicle generation. Immunity. (2017) 47:51-65.e7. doi: 10.1016/j.immuni.2017.06.001

57. Zhou W, Yuan J. Necroptosis in health and diseases. Semin Cell Dev Biol. (2014) 35:14-23. doi: 10.1016/j.semcdb.2014.07.013

58. Ding J, Wang K, Liu W, She Y, Sun Q, Shi J, et al. Pore-forming activity and structural autoinhibition of the gasdermin family. Nature. (2016) 535:111-6. doi: 10.1038/nature 18590

59. Ostermann M, Liu K. Pathophysiology of AKI. Best Pract Res Clin Anaesthesiol. (2017) 31:305-14. doi: 10.1016/j.bpa.2017.09.001

60. Simon N, Hertig A. Alteration of fatty acid oxidation in tubular epithelial cells: from acute kidney injury to renal fibrogenesis. Front Med. (2015) 2:52. doi: 10.3389/fmed.2015.00052

61. Yang L, Besschetnova TY, Brooks CR, Shah JV, Bonventre JV. Epithelial cell cycle arrest in G2/M mediates kidney fibrosis after injury. Nat Med. (2010) 16:535-43. doi: 10.1038/nm.2144

62. Payen D, Lukaszewicz A-C, Legrand M, Gayat E, Faivre V, Megarbane B, et al. A multicentre study of acute kidney injury in severe sepsis and septic shock: association with inflammatory phenotype and HLA genotype. PLOS ONE. (2012) 7:e35838. doi: 10.1371/journal.pone.0035838

63. Imig JD, Ryan MJ. Immune and inflammatory role in renal disease. Compr Physiol. (2013) 3:957-76. doi: 10.1002/cphy.c120028

64. Herter JM, Rossaint J, Spieker T, Zarbock A. Adhesion molecules involved in neutrophil recruitment during sepsis-induced acute kidney injury. J Innate Immun. (2014) 6:597-606. doi: 10.1159/000358238

65. Umbro I, Gentile G, Tinti F, Muiesan P, Mitterhofer AP. Recent advances in pathophysiology and biomarkers of sepsis-induced acute kidney injury. $J$ Infect. (2016) 72:131-42. doi: 10.1016/j.jinf.2015.11.008

66. Tang D, Kang R, Coyne CB, Zeh HJ, Lotze MT. PAMPs and DAMPs: signal 0s that spur autophagy and immunity. Immunol Rev. (2012) 249:158-75. doi: 10.1111/j.1600-065X.2012.01146.x 
67. Tonnus W, Gembardt F, Latk M, Parmentier S, Hugo C, Bornstein SR, et al. The clinical relevance of necroinflammation-highlighting the importance of acute kidney injury and the adrenal glands. Cell Death Differ. (2019) 26:68-82. doi: 10.1038/s41418-018-0193-5

68. Sundén-Cullberg J, Norrby-Teglund A, Rouhiainen A, Rauvala H, Herman G, Tracey KJ, et al. Persistent elevation of high mobility group box-1 protein (HMGB1) in patients with severe sepsis and septic shock. Crit Care Med. (2005) 33:564-73. doi: 10.1097/01.CCM.0000155991.88802.4D

69. Ekaney ML, Otto GP, Sossdorf M, Sponholz C, Boehringer M, Loesche $\mathrm{W}$, et al. Impact of plasma histones in human sepsis and their contribution to cellular injury and inflammation. Crit Care. (2014) 18:543. doi: 10.1186/s13054-014-0543-8

70. Sursal T, Stearns-Kurosawa DJ, Itagaki K, Oh S-Y, Sun S, Kurosawa S, et al. Plasma bacterial and mitochondrial DNA distinguish bacterial sepsis from sterile SIRS and quantify inflammatory tissue injury in nonhuman primates. Shock Augusta Ga. (2013) 39:55-62. doi: 10.1097/SHK.0b013e3182 $76 \mathrm{f} 4 \mathrm{ca}$

71. Gentile LF, Moldawer LL. DAMPS, PAMPS and the origins of SIRS in bacterial sepsis. Shock Augusta Ga. (2013) 39:113-4. doi: 10.1097/SHK.0b013e318277109c

72. Murugan R, Karajala-Subramanyam V, Lee M, Yende S, Kong L, Carter M, et al. Acute kidney injury in non-severe pneumonia is associated with an increased immune response and lower survival. Kidney Int. (2010) 77:52735. doi: 10.1038/ki.2009.502

73. Messmer D, Yang H, Telusma G, Knoll F, Li J, Messmer B, et al. High mobility group box protein 1: an endogenous signal for dendritic cell maturation and Th1 polarization. J Immunol. (2004) 173:307-13. doi: 10.4049/jimmunol.173.1.307

74. Leelahavanichkul A, Huang Y, Hu X, Zhou H, Tsuji T, Chen R, et al. Chronic kidney disease-induced HMGB1 elevation worsens sepsis and sepsis-induced acute kidney injury. Kidney Int. (2011) 80:1198-211. doi: 10.1038/ki.2011.261

75. Vénéreau E, Ceriotti C, Bianchi ME. DAMPs from cell death to new life. Front Immunol. (2015) 6:422. doi: 10.3389/fimmu.2015.00422

76. Schiraldi M, Raucci A, Muñoz LM, Livoti E, Celona B, Venereau E, et al. HMGB1 promotes recruitment of inflammatory cells to damaged tissues by forming a complex with CXCL12 and signaling via CXCR4. J Exp Med. (2012) 209:551-63. doi: 10.1084/jem.20111739

77. Kazama H, Ricci J-E, Herndon JM, Hoppe G, Green DR, Ferguson TA. Induction of immunological tolerance by apoptotic cells requires caspasedependent oxidation of high-mobility group box-1 protein. Immunity. (2008) 29:21-32. doi: 10.1016/j.immuni.2008.05.013

78. Bell CW, Jiang W, Reich CF, Pisetsky DS. The extracellular release of HMGB1 during apoptotic cell death. Am J Physiol Cell Physiol. (2006) 291:C1318-25. doi: 10.1152/ajpcell.00616.2005

79. Qin S, Wang H, Yuan R, Li H, Ochani M, Ochani K, et al. Role of HMGB1 in apoptosis-mediated sepsis lethality. J Exp Med. (2006) 203:1637-42. doi: 10.1084/jem.20052203

80. Allam R, Scherbaum CR, Darisipudi MN, Mulay SR, Hägele H, Lichtnekert $\mathrm{J}$, et al. Histones from dying renal cells aggravate kidney injury via TLR2 and TLR4. J Am Soc Nephrol. (2012) 23:1375-88. doi: 10.1681/ASN.2011111077

81. Nakazawa D, Kumar SV, Marschner J, Desai J, Holderied A, Rath L, et al. Histones and neutrophil extracellular traps enhance tubular necrosis and remote organ injury in ischemic AKI. J Am Soc Nephrol. (2017) 28:1753-68. doi: 10.1681/ASN.2016080925

82. Xu J, Zhang X, Pelayo R, Monestier M, Ammollo CT, Semeraro F, et al. Extracellular histones are major mediators of death in sepsis. Nat Med. (2009) 15:1318-21. doi: 10.1038/nm.2053

83. Moreth K, Frey H, Hubo M, Zeng-Brouwers J, Nastase M-V, Hsieh LT$\mathrm{H}$, et al. Biglycan-triggered TLR-2- and TLR-4-signaling exacerbates the pathophysiology of ischemic acute kidney injury. Matrix Biol J Int Soc Matrix Biol. (2014) 35:143-51. doi: 10.1016/j.matbio.2014.01.010

84. Babelova A, Moreth K, Tsalastra-Greul W, Zeng-Brouwers J, Eickelberg $\mathrm{O}$, Young MF, et al. Biglycan, a danger signal that activates the NLRP3 inflammasome via Toll-like and P2X receptors. J Biol Chem. (2009) 284:24035-48. doi: 10.1074/jbc.M109.014266

85. Schaefer L, Babelova A, Kiss E, Hausser H-J, Baliova M, Krzyzankova M, et al. The matrix component biglycan is proinflammatory and signals through
Toll-like receptors 4 and 2 in macrophages. J Clin Invest. (2005) 115:2223-33. doi: 10.1172/JCI23755

86. Schaefer L, Macakova K, Raslik I, Micegova M, Gröne H-J, Schönherr $\mathrm{E}$, et al. Absence of decorin adversely influences tubulointerstitial fibrosis of the obstructed kidney by enhanced apoptosis and increased inflammatory reaction. Am J Pathol. (2002) 160:1181-91. doi: 10.1016/S0002-9440(10)64937-1

87. Merline R, Moreth K, Beckmann J, Nastase MV, Zeng-Brouwers J, Tralhão $\mathrm{JG}$, et al. Signaling by the matrix proteoglycan decorin controls inflammation and cancer through PDCD4 and microRNA-21. Sci Signal. (2011) 4:ra75. doi: 10.1126/scisignal.2001868

88. Jansen MPB, Pulskens WP, Butter LM, Florquin S, Juffermans NP, Roelofs JJTH, et al. Mitochondrial DNA is released in urine of SIRS patients with acute kidney injury and correlates with severity of renal dysfunction. Shock. (2018) 49:301-10. doi: 10.1097/SHK.0000000000000967

89. Shi C, Kim T, Steiger S, Mulay SR, Klinkhammer BM, Bäuerle T, et al. Crystal clots as therapeutic target in cholesterol crystal embolism. Circ Res. (2020) 126:e37-52. doi: 10.1161/CIRCRESAHA.119.315625

90. Tsuji N, Tsuji T, Ohashi N, Kato A, Fujigaki Y, Yasuda H. Role of mitochondrial DNA in septic AKI via Toll-like receptor 9. J Am Soc Nephrol. (2016) 27:2009-20. doi: 10.1681/ASN.2015040376

91. El-Achkar TM, Wu XR. Uromodulin in kidney injury: an instigator, bystander, or protector? Am J Kidney Dis. (2012) 59:452-61. doi: 10.1053/j.ajkd.2011.10.054

92. Säemann MD, Weichhart T, Zeyda M, Staffler G, Schunn M, Stuhlmeier KM, et al. Tamm-Horsfall glycoprotein links innate immune cell activation with adaptive immunity via a Toll-like receptor-4-dependent mechanism. J Clin Invest. (2005) 115:468-75. doi: 10.1172/JCI200522720

93. Darisipudi MN, Thomasova D, Mulay SR, Brech D, Noessner E, Liapis $\mathrm{H}$, et al. Uromodulin triggers IL-1 $\beta$-dependent innate immunity via the NLRP3 inflammasome. J Am Soc Nephrol. (2012) 23:1783-9. doi: 10.1681/ASN.2012040338

94. Feldman N, Rotter-Maskowitz A, Okun E. DAMPs as mediators of sterile inflammation in aging-related pathologies. Ageing Res Rev. (2015) 24:29-39. doi: 10.1016/j.arr.2015.01.003

95. Muller William A. Mechanisms of transendothelial migration of leukocytes. Circ Res. (2009) 105:223-30. doi: 10.1161/CIRCRESAHA.109.200717

96. Anders H-J. Toll-like receptors and danger signaling in kidney injury. J Am Soc Nephrol. (2010) 21:1270-4. doi: 10.1681/ASN.2010030233

97. McDonald B, Pittman K, Menezes GB, Hirota SA, Slaba I, Waterhouse $\mathrm{CCM}$, et al. Intravascular danger signals guide neutrophils to sites of sterile inflammation. Science. (2010) 330:362-6. doi: 10.1126/science.1195491

98. Krausgruber T, Blazek K, Smallie T, Alzabin S, Lockstone H, Sahgal N, et al. IRF5 promotes inflammatory macrophage polarization and T H 1-T H 17 responses. Nat Immunol. (2011) 12:231-8. doi: 10.1038/ni.1990

99. Sorokin L. The impact of the extracellular matrix on inflammation. Nat Rev Immunol. (2010) 10:712-23. doi: 10.1038/nri2852

100. Anders H-J, Ryu M. Renal microenvironments and macrophage phenotypes determine progression or resolution of renal inflammation and fibrosis. Kidney Int. (2011) 80:915-25. doi: 10.1038/ki.2011.217

101. Singbartl K, Bishop JV, Wen X, Murugan R, Chandra S, Filippi M-D, et al. Differential effects of kidney-lung cross-talk during acute kidney injury and bacterial pneumonia. Kidney Int. (2011) 80:633-44. doi: 10.1038/ki.2011.201

102. Al-Harbi NO, Nadeem A, Ahmad SF, Alanazi MM, Aldossari AA, Alasmari F. Amelioration of sepsis-induced acute kidney injury through inhibition of inflammatory cytokines and oxidative stress in dendritic cells and neutrophils respectively in mice: role of spleen tyrosine kinase signaling. Biochimie. (2019) 158:102-10. doi: 10.1016/j.biochi.2018.12.014

103. Anders H-J, Schaefer L. Beyond tissue injury-damage-associated molecular patterns, Toll-like receptors, and inflammasomes also drive regeneration and fibrosis. J Am Soc Nephrol. (2014) 25:1387-400. doi: 10.1681/ASN.2014010117

104. Mulay SR, Linkermann A, Anders H-J. Necroinflammation in kidney disease. J Am Soc Nephrol. (2016) 27:27-39. doi: 10.1681/ASN.2015040405

105. Wu H, Ma J, Wang P, Corpuz TM, Panchapakesan U, Wyburn $\mathrm{KR}$, et al. HMGB1 contributes to kidney ischemia reperfusion injury. J Am Soc Nephrol. (2010) 21:1878-90. doi: 10.1681/ASN.2009 101048 
106. Nakazawa D, Shida H, Kusunoki Y, Miyoshi A, Nishio S, Tomaru U, et al. The responses of macrophages in interaction with neutrophils that undergo NETosis. J Autoimmun. (2016) 67:19-28. doi: 10.1016/j.jaut.2015.08.018

107. Leibovich SJ, Chen J-F, Pinhal-Enfield G, Belem PC, Elson G, Rosania A, et al. Synergistic up-regulation of vascular endothelial growth factor expression in murine macrophages by adenosine $\mathrm{A} 2 \mathrm{~A}$ receptor agonists and endotoxin. Am J Pathol. (2002) 160:2231-44. doi: 10.1016/S0002-9440(10)61170-4

108. Lazzeri E, Angelotti ML, Peired A, Conte C, Marschner JA, Maggi L, et al. Endocycle-related tubular cell hypertrophy and progenitor proliferation recover renal function after acute kidney injury. Nat Commun. (2018) 9:1344. doi: 10.1038/s41467-018-03753-4

109. Edgar BA, Zielke N, Gutierrez C. Endocycles: a recurrent evolutionary innovation for post-mitotic cell growth. Nat Rev Mol Cell Biol. (2014) 15:197-210. doi: 10.1038/nrm3756

110. Liu KD. Molecular mechanisms of recovery from acute renal failure. Crit Care Med. (2003) 31(8 Suppl.):S572-81. doi: 10.1097/01.CCM.0000081592.36382.BC

111. Meng X-M, Tang PM-K, Li J, Lan HY. Macrophage phenotype in kidney injury and repair. Kidney Dis. (2015) 1:138-46. doi: 10.1159/000431214

112. Lee S, Huen S, Nishio H, Nishio S, Lee HK, Choi B-S, et al. Distinct macrophage phenotypes contribute to kidney injury and repair. J Am Soc Nephrol. (2011) 22:317-26. doi: 10.1681/ASN.2009060615

113. Werner S, Grose R. Regulation of wound healing by growth factors and cytokines. Physiol Rev. (2003) 83:835-70. doi: 10.1152/physrev.2003.83.3.835

114. Li X, Mu G, Song C, Zhou L, He L, Jin Q, et al. Role of M2 Macrophages in sepsis-induced acute kidney injury. Shock. (2018) 50:233-9. doi: 10.1097/SHK.0000000000001006

115. Zhang M-Z, Yao B, Wang S, Fan X, Wu G, Yang H, et al. Intrarenal dopamine deficiency leads to hypertension and decreased longevity in mice. J Clin Invest. (2011) 121:2845-54. doi: 10.1172/JCI57324

116. Micanovic R, Khan S, Janosevic D, Lee ME, Hato T, Srour EF, et al. Tammhorsfall protein regulates mononuclear phagocytes in the kidney. J Am Soc Nephrol. (2018) 29:841-56. doi: 10.1681/ASN.2017040409

117. Wang Y, Zhang Y. Kidney and innate immunity. Immunol Lett. (2017) 183:73-8. doi: 10.1016/j.imlet.2017.01.011

118. Angelotti ML, Ronconi E, Ballerini L, Peired A, Mazzinghi B, Sagrinati C, et al. Characterization of renal progenitors committed toward tubular lineage and their regenerative potential in renal tubular injury. Stem Cells. (2012) 30:1714-25. doi: 10.1002/stem.1130

119. Sallustio F, Benedictis LD, Castellano G, Zaza G, Loverre A, Costantino $\mathrm{V}$, et al. TLR2 plays a role in the activation of human resident renal stem/progenitor cells. FASEB J. (2010) 24:514-25. doi: 10.1096/fj.09-136481

120. Morigi M, Imberti B, Zoja C, Corna D, Tomasoni S, Abbate M, et al. Mesenchymal stem cells are renotropic, helping to repair the kidney and improve function in acute renal failure. J Am Soc Nephrol. (2004) 15:1794804. doi: 10.1097/01.ASN.0000128974.07460.34

121. Humphreys BD, Bonventre JV. Mesenchymal stem cells in acute kidney injury. Annu Rev Med. (2008) 59:311-25. doi: 10.1146/annurev.med.59.061506.154239

122. Kulkarni OP, Hartter I, Mulay SR, Hagemann J, Darisipudi MN, Kumar VR S, et al. Toll-like receptor 4-induced IL-22 accelerates kidney regeneration. J Am Soc Nephrol. (2014) 25:978-89. doi: 10.1681/ASN.2013050528

123. Dudakov JA, Hanash AM, van den Brink MRM. Interleukin-22: immunobiology and pathology. Annu Rev Immunol. (2015) 33:747-85. doi: 10.1146/annurev-immunol-032414-112123

124. Weber GF, Schlautkötter S, Kaiser-Moore S, Altmayr F, Holzmann B, Weighardt $H$. Inhibition of interleukin-22 attenuates bacterial load and organ failure during acute polymicrobial sepsis. Infect Immun. (2007) 75:1690-7. doi: 10.1128/IAI.01564-06

125. Anderberg SB, Luther T, Frithiof R. Physiological aspects of Toll-like receptor 4 activation in sepsis-induced acute kidney injury. Acta Physiol. (2017) 219:575-90. doi: 10.1111/apha.12798
126. Yang $\mathrm{H}$, Wang $\mathrm{H}$, Andersson U. Targeting inflammation driven by HMGB1. Front Immunol. (2020) 11:484. doi: 10.3389/fimmu.2020.00484

127. Gentile LF, Moldawer LL. HMGB1 as a therapeutic target for sepsis: it's all in the timing! Expert Opin Ther Targets. (2014) 18:243-5. doi: $10.1517 / 14728222.2014 .883380$

128. Wang H, Bloom O, Zhang M, Vishnubhakat JM, Ombrellino M, Che J, et al. HMG-1 as a late mediator of endotoxin lethality in mice. Science. (1999) 285:248-51. doi: 10.1126/science.285.5425.248

129. Yang H, Ochani M, Li J, Qiang X, Tanovic M, Harris HE, et al. Reversing established sepsis with antagonists of endogenous high-mobility group box 1. Proc Natl Acad Sci USA. (2004) 101:296-301. doi: 10.1073/pnas.24346 51100

130. Yang H, Wang H, Ju Z, Ragab AA, Lundbäck P, Long W, et al. MD-2 is required for disulfide HMGB1-dependent TLR4 signaling. J Exp Med. (2015) 212:5-14. doi: 10.1084/jem.20141318

131. Li W, Ashok M, Li J, Yang H, Sama AE, Wang H. A major ingredient of green tea rescues mice from lethal sepsis partly by inhibiting HMGB1. PLoS ONE. (2007) 2:e1153. doi: 10.1371/journal.pone.0001153

132. Picher M, Burch LH, Hirsh AJ, Spychala J, Boucher RC. Ecto 5 ' -nucleotidase and nonspecific alkaline phosphatase two AMP-hydrolysing ectoenzymes with distinct roles in human airways. J Biol Chem. (2003) 278:13468-79. doi: 10.1074/jbc.M300569200

133. Koyama I, Matsunaga T, Harada T, Hokari S, Komoda T. Alkaline phosphatases reduce toxicity of lipopolysaccharides in vivo and in vitro through dephosphorylation. Clin Biochem. (2002) 35:455-61. doi: 10.1016/S0009-9120(02)00330-2

134. Peters E, Masereeuw R, Pickkers P. The potential of alkaline phosphatase as a treatment for sepsis-associated acute kidney injury. Nephron Clin Pract. (2014) 127:144-8. doi: 10.1159/000363256

135. Pickkers P, Mehta RL, Murray PT, Joannidis M, Molitoris BA, Kellum JA, et al. Effect of human recombinant alkaline phosphatase on 7-day creatinine clearance in patients with sepsis-associated acute kidney injury: a randomized clinical trial. JAMA. (2018) 320:1998-2009. doi: 10.1001/jama.2018.14283

136. Akbar SR, Long DM, Hussain K, Alhajhusain A, Ahmed US, Iqbal HI, et al. Hyperuricemia: an early marker for severity of illness in sepsis. Int J Nephrol. (2015) 2015:301021. doi: 10.1155/2015/301021

137. Hahn K, Kanbay M, Lanaspa MA, Johnson RJ, Ejaz AA. Serum uric acid and acute kidney injury: a mini review. J Adv Res. (2017) 8:529-36. doi: 10.1016/j.jare.2016.09.006

138. Pehlivanlar-Kucuk M, Kucuk AO, Ozturk CE, Er MC, Ulger F. The association between serum uric acid level and prognosis in critically ill patients, uric acid as a prognosis predictor. Clin Lab. (2018) 64:1491-500. doi: 10.7754/Clin.Lab.2018.180334

139. Srivastava A, Palsson R, Leaf DE, Higuera A, Chen ME, Palacios P, et al. Uric acid and acute kidney injury in the critically ill. Kidney Med. (2019) 1:21-30. doi: 10.1016/j.xkme.2019.01.003

140. Patel S. Danger-associated molecular patterns (DAMPs): the derivatives and triggers of inflammation. Curr Allergy Asthma Rep. (2018) 18:63. doi: $10.1007 /$ s11882-018-0817-3

Conflict of Interest: The authors declare that the research was conducted in the absence of any commercial or financial relationships that could be construed as a potential conflict of interest.

Copyright (c) 2021 Ludes, de Roquetaillade, Chousterman, Pottecher and Mebazaa. This is an open-access article distributed under the terms of the Creative Commons Attribution License (CC BY). The use, distribution or reproduction in other forums is permitted, provided the original author(s) and the copyright owner(s) are credited and that the original publication in this journal is cited, in accordance with accepted academic practice. No use, distribution or reproduction is permitted which does not comply with these terms. 